\title{
elsevier_MICROC_2131
}

\section{One-million year Rare Earth Element stratigraphies along an Antarctic marine sediment core}

Francesco Rugi $^{\mathrm{a}}$

Roberto Udisti ${ }^{\mathrm{a}}$

Silvia Becaglia

Daniele Frosinia

Giovanna Giorgetti ${ }^{b}$

Gerhard Kuhn ${ }^{c}$

Miriam Marconia

Donata Monien ${ }^{d}$

Silvia Nava ${ }^{\mathrm{e}}$

Mirko Severia

Franco Talarico

Rita Traversi ${ }^{a, *}$

rita.traversi@unifi.it

aDepartment of Chemistry "Ugo Schiff", University of Florence, Via della Lastruccia, 3, I-50019 Sesto Fiorentino (FI), Italy

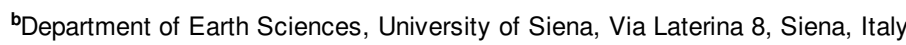

cAlfred Wegener Institute for Polar and Marine Research, Am Alten Hafen 26, Bremerhaven, Germany

dInstitute for Chemistry and Biology of the Marine Environment, Carl-von-Ossietzky University Oldenburg, Carl-von-Ossietzky Straße 9-11, 26129 Oldenburg, Germany

eDepartment of Physics and Astronomy, University of Florence and National Institute of Nuclear Physics (INFN), Via G. Sansone 1, 50019 Sesto Fiorentino (Fi), Italy

*Corresponding author. Tel.: + $390554573381,+393478747270$ (mobile)

\section{Abstract}

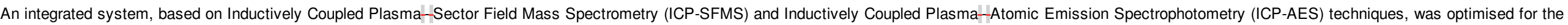

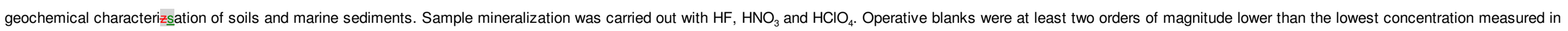

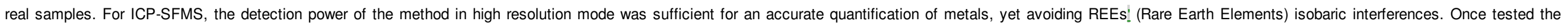
accuracy on six certified materials, the methods were applied to the analysis of 39 major and trace metals on the top $90 \mathrm{~m}$ of sediments from the ANDRILL AND-1B core, covering the last million years.

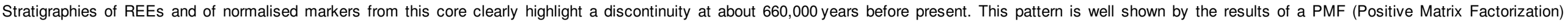

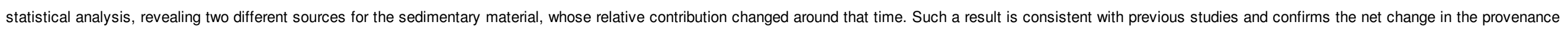
of glacial fluxes in the McMurdo region (Ross Ice Shelf, Antarctica) in the last million years. 


\section{Introduction}

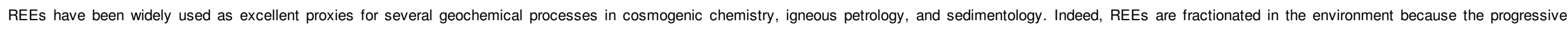

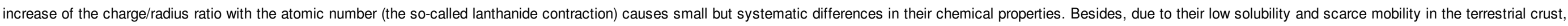
REEs display a conservative behaviour in the environment [7]. As a consequence, REEs! abundance varies in weathering products, and their relative changes are used as a marker of source rocks [16,31].

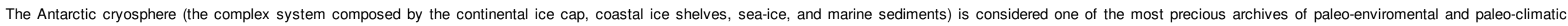

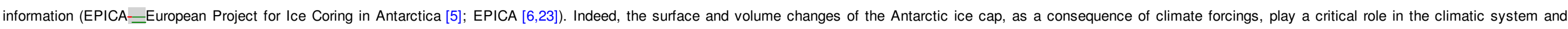

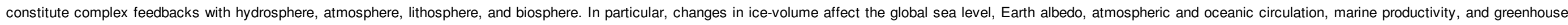
gas emissions and uptake processes. Such environmental changes, in turn, affect the solar irradiance budget and the global transport and distribution of matter and energy [1,12].

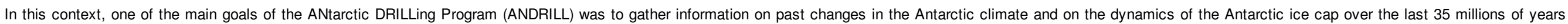

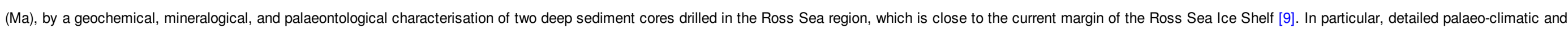

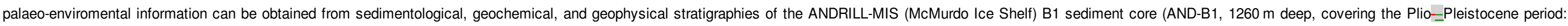
0-15 million years $\mathrm{Ma}$ ago), composed by glaciomarine, terrigenous, volcanic, and biogenic sediment that has accumulated in the Windless Bight region of a flexural moat basin surrounding Ross Island.

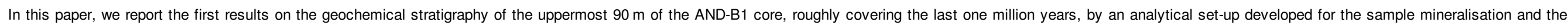
determination of 39 major and trace elements, including REEs.

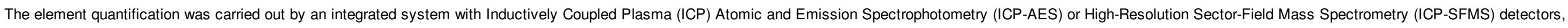
depending on element concentrations and interferences.

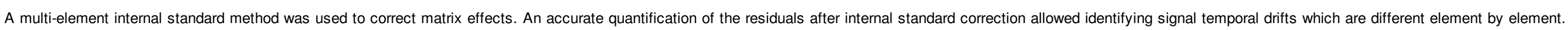

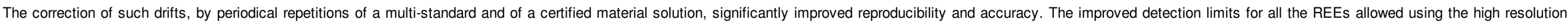
technique $(10,000 \mathrm{~m} / \Delta \mathrm{m})$ in their determination by ICP-MS, hence avoiding possible isobaric interferences.

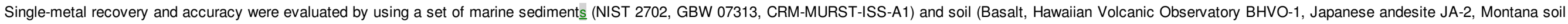
NIST 2711) certified materials; the results are reported in Tables 1 and 2 in the Supplementary material.

\section{Materials and methods}

Sample mineralisation was carried out with a mixture of ultrapure $\mathrm{HNO}_{3}\left(69.5 \%\right.$ reagent grade, purified by sub-boiling distillation $=\mathrm{s}-\mathrm{b} \mathrm{d}$.), $\mathrm{HF} 40 \%$ (Suprapur grade), and $\mathrm{HClO}{ }_{4} 70 \%$ (Suprapur grade).

Three internal standards were used for ICP-SFMS analyses (In, Re and Ge at 12, 30, and $60 \mu \mathrm{g} \mathrm{L}=1$, respectively) and a mono-element internal standard (Ge, $5 \mathrm{mg} \mathrm{L=}=1$ ) was used for ICP-AES analyses.

Detailed information about reagents and standard solutions are reported in the Supplementary material.

\subsection{Instrumentation}

Analytical measurements were carried out using a Sector-Field ICP mass spectrometer and an ICP-AES spectrophotometer. The instrumental set-up conditions are reported in Table 3 in the Supplementary material.

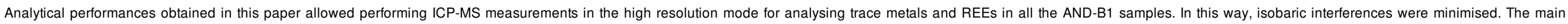

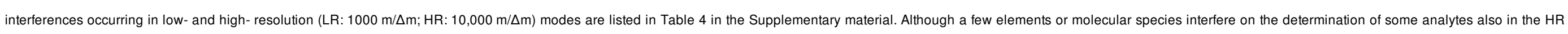
mode, they are present in soils and marine sediments at very low concentrations and their contribution to the analytical signal is negligible (at least, two orders of magnitude lower than the background levels).

\subsection{Method set-up}




\section{elsevier_MICROC_2131}

\subsubsection{Sample mineralisation}

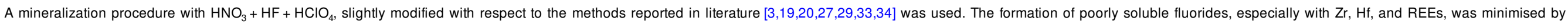

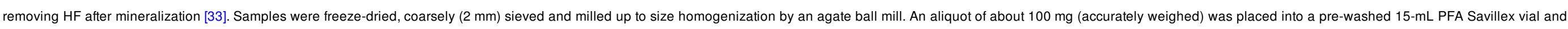

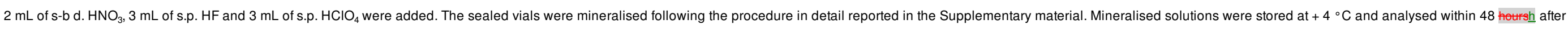
dissolution.

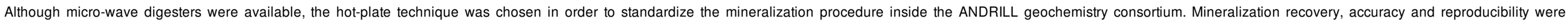
successfully tested on certificated materials.

\subsubsection{Reproducibility, detection limits and reagent blank}

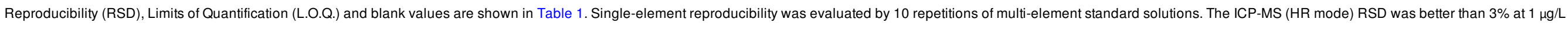

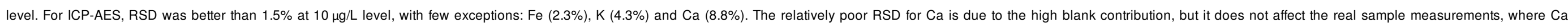
concentrations are as high as $1 \mathrm{mg} / \mathrm{L}$ (see below).

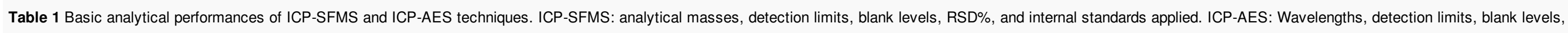
RSD\%, and internal standards applied.

\begin{tabular}{|c|c|c|c|c|c|}
\hline \multicolumn{6}{|c|}{ ICP-SFMS Finnigan MAT Element2 } \\
\hline Element & Analytical mass & D.L. $\left(n g L^{=}=1\right)$ & Blank (ng L= $=1$ ) & $\mathrm{RSD} \%(1 \mu \mathrm{g} \mathrm{L}=1)$ & Internal standard \\
\hline $\mathrm{Ce}$ & ${ }^{140} \mathrm{Ce}$ & 8.4 & d.l. & 0.8 & ${ }^{115} \mathrm{ln}$ \\
\hline $\mathrm{Cr}$ & ${ }^{52} \mathrm{Cr}$ & 9.1 & 127.9 & 1.1 & ${ }^{115} / \mathrm{n}$ \\
\hline Cs & ${ }^{133} \mathrm{Cs}$ & 3.6 & d.I. & 1.1 & ${ }^{115} \mathrm{In}$ \\
\hline Dy & ${ }^{163} \mathrm{Dy}$ & 10 & d.l. & 2.0 & ${ }^{185} \mathrm{Re}$ \\
\hline Er & ${ }^{166} \mathrm{Er}$ & 9.9 & d.l. & 2.2 & ${ }^{185} \mathrm{Re}$ \\
\hline $\mathrm{Eu}$ & ${ }^{151} \mathrm{Eu}$ & 11.2 & d.l. & 1.7 & ${ }^{115} \mathrm{n}$ \\
\hline Gd & ${ }^{157} \mathrm{Gd}$ & 15.6 & d.l. & 1.6 & ${ }^{115} \mathrm{n}$ \\
\hline $\mathrm{Hf}$ & ${ }^{178} \mathrm{Hf}$ & 13.8 & 38 & 2.3 & ${ }^{185} \mathrm{Re}$ \\
\hline Ho & ${ }^{65} \mathrm{Ho}$ & 7 & d.l. & 1.1 & ${ }^{185} \mathrm{Re}$ \\
\hline La & ${ }^{139} \mathrm{La}$ & 10.4 & d.l. & 1.3 & $115 \mathrm{n}$ \\
\hline Lu & ${ }^{175} \mathrm{Lu}$ & 5.4 & d.l. & 1.5 & ${ }^{185} \mathrm{Re}$ \\
\hline $\mathrm{Nb}$ & ${ }^{93} \mathrm{Nb}$ & 6.7 & 27.8 & 0.8 & ${ }^{72} \mathrm{Ge}$ \\
\hline $\mathrm{Nd}$ & ${ }^{146} \mathrm{Nd}$ & 13.9 & d.l. & 2.7 & $115 \mathrm{n}$ \\
\hline $\mathrm{Ni}$ & ${ }^{60} \mathrm{Ni}$ & 15 & 133.6 & 2.5 & ${ }^{72} \mathrm{Ge}$ \\
\hline $\operatorname{Pr}$ & ${ }^{141} \mathrm{Pr}$ & 5.9 & d.l. & 0.8 & ${ }^{115} \mathrm{In}$ \\
\hline $\mathrm{Rb}$ & ${ }^{85} \mathrm{Rb}$ & 12 & 20.9 & 1.3 & ${ }^{72} \mathrm{Ge}$ \\
\hline
\end{tabular}




\section{elsevier_MICROC_2131}

\begin{tabular}{|c|c|c|c|c|c|}
\hline $\mathrm{Sc}$ & ${ }^{45} \mathrm{Sc}$ & 9 & 11.3 & 1.3 & ${ }^{72} \mathrm{Ge}$ \\
\hline Sm & ${ }^{147} \mathrm{Sm}$ & 14.2 & d.l. & 2.0 & $115 \mathrm{ln}$ \\
\hline $\mathrm{Ta}$ & ${ }^{181} \mathrm{Ta}$ & 6.4 & 38 & 1.4 & ${ }^{185} \mathrm{Re}$ \\
\hline $\mathrm{Tb}$ & ${ }^{159} \mathrm{~Tb}$ & 5.8 & d.l. & 1.4 & ${ }^{185} \mathrm{Re}$ \\
\hline Th & ${ }^{232} \mathrm{Th}$ & 11 & d.l. & 1.3 & ${ }^{185} \mathrm{Re}$ \\
\hline Tm & ${ }^{169} \mathrm{Tm}$ & 6.9 & d.l. & 1.3 & ${ }^{185} \mathrm{Re}$ \\
\hline U & ${ }^{238} \mathrm{U}$ & 4 & d.l. & 1.3 & ${ }^{185} \mathrm{Re}$ \\
\hline Y & ${ }^{89} Y$ & 7 & d.l. & 1.2 & ${ }^{72} \mathrm{Ge}$ \\
\hline $\mathrm{Yb}$ & ${ }^{172} \mathrm{Yb}$ & 8.9 & d.l. & 1.4 & ${ }^{185} \mathrm{Re}$ \\
\hline $\mathrm{Zr}$ & ${ }^{90} \mathrm{Zr}$ & 18.9 & 254.1 & 1.6 & ${ }^{72} \mathrm{Ge}$ \\
\hline \multicolumn{6}{|c|}{ ICP-AES Varian 720-ES } \\
\hline Element & Wavelength $(\mathrm{nm})$ & D.L. $(\mu g \mathrm{~L}=1)$ & Blank ( $\mu g \mathrm{~L}=1$ ) & RSD \% $\left(10 \mu g L^{=1}\right)$ & Internal standard (nm) \\
\hline $\mathrm{Al}$ & 396.152 & 0.46 & 1.8 & 0.8 & Ge 209.426 \\
\hline $\mathrm{Ba}$ & 455.403 & 0.023 & 0.11 & 0.1 & Ge 209.426 \\
\hline $\mathrm{Be}$ & 313.107 & 0.016 & 0.019 & 0.1 & Ge 209.426 \\
\hline $\mathrm{Ca}$ & 317.933 & 0.68 & 7.1 & 8.8 & Ge 209.426 \\
\hline Co & 230.786 & 0.28 & 0.38 & 0.6 & Ge 209.426 \\
\hline $\mathrm{Fe}$ & 238.204 & 0.14 & 1.3 & 2.3 & Ge 209.426 \\
\hline $\mathrm{K}$ & 766.491 & 0.51 & 1.8 & 4.3 & Ge 209.426 \\
\hline $\mathrm{Li}$ & 670.783 & 0.034 & 0.39 & 0.3 & Ge 209.426 \\
\hline $\mathrm{Mg}$ & 285.213 & 0.13 & 0.9 & 0.6 & Ge 209.426 \\
\hline $\mathrm{Mn}$ & 257.61 & 0.029 & 0.1 & 0.2 & Ge 209.426 \\
\hline $\mathrm{Na}$ & 588.995 & 0.25 & 2.1 & 1.5 & Ge 209.426 \\
\hline $\mathrm{Sr}$ & 407.771 & 0.019 & 0.089 & 0.2 & Ge 209.426 \\
\hline $\mathrm{Ti}$ & 336.122 & 0.079 & 0.28 & 0.4 & Ge 209.426 \\
\hline
\end{tabular}

L.O.Q. values were calculated as $10 \sigma$ of 10 repetitions of one standard solution containing $40 \mathrm{ng} \mathrm{L}^{=1}{ }^{1}$ (ICP-SFMS) or $2 \mu \mathrm{L} \mathrm{L}^{\mathrm{I}}=1$ (ICP-AES) of each element.

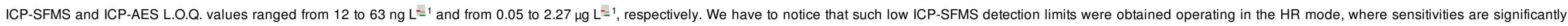
lower than those gained by LR techniques (e.g., ICP-QMS) but working in the HR mode allowed minimising the isobaric interferences.

Reagent blank values were at least two orders of magnitude lower than their minimum concentrations measured in the samples and in the certified materials (Table 1).

\subsubsection{Real-sample improved quantification procedure}

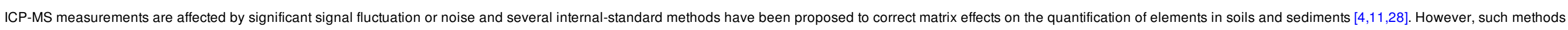




\section{elsevier_MICROC_2131}

do not account for the residual noise after internal-standard correction.

Here, we discussed and quantified the residual noise and applied a successful correction by using a suitable internal standard procedure.

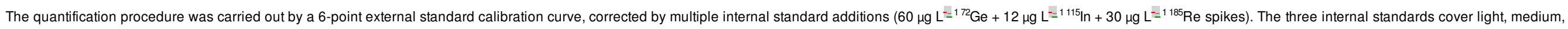
and heavy isotopic mass ranges, but the most suitable internal standard was chosen as a function of the single element (see last column in Table 1).

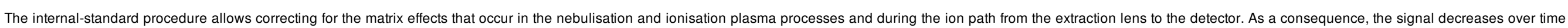

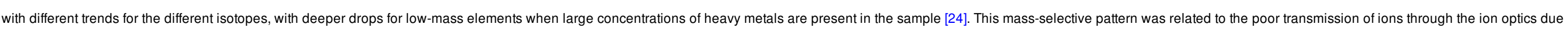
to matrix-induced space-charge effects [30].

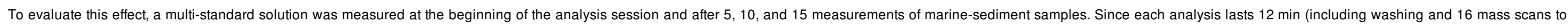

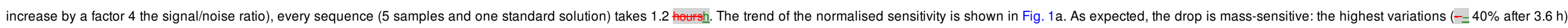

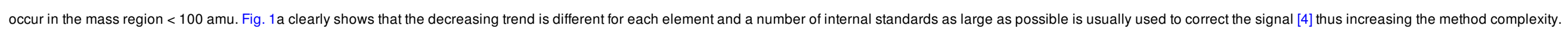

a

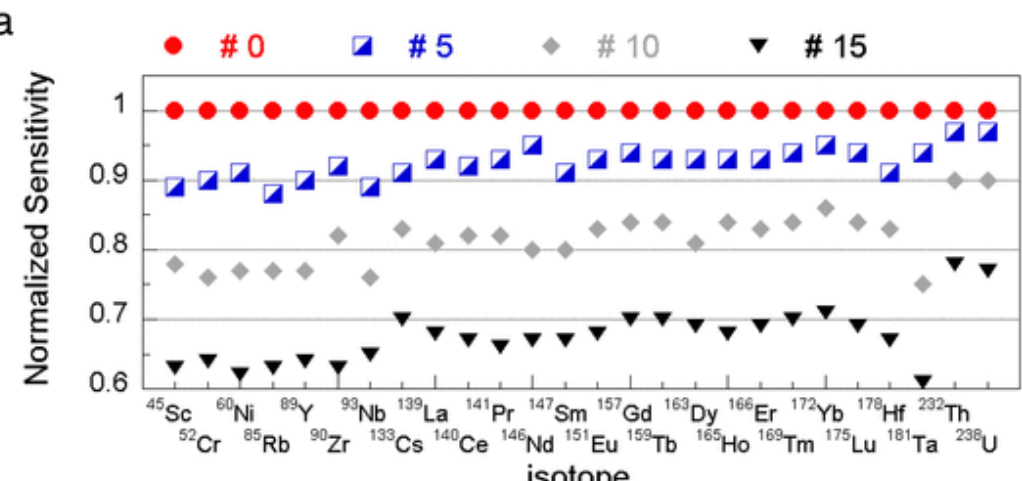

b

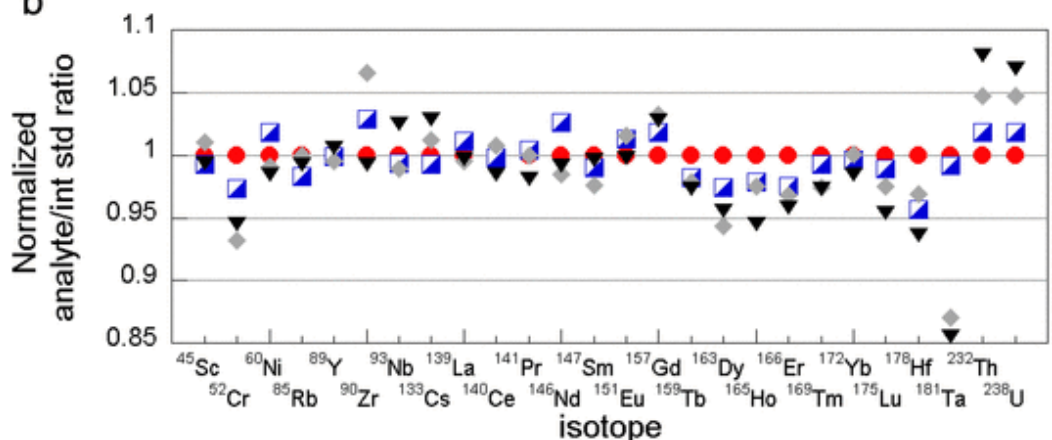

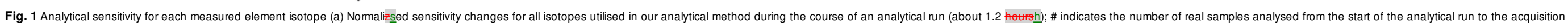

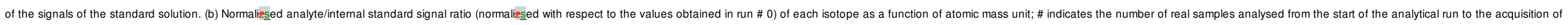
the signals of the standard solution.

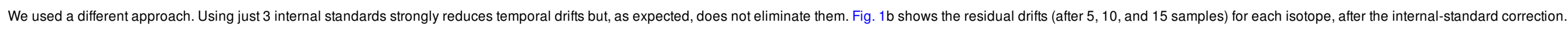

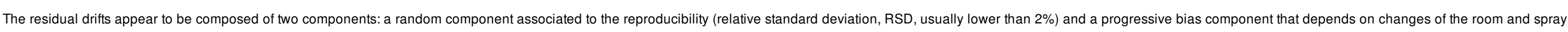




\section{elsevier_MICROC_2131}

chamber temperatures, detector response, and cone occlusion.

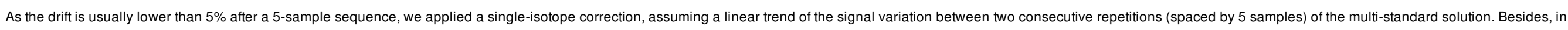
order to monitor the accuracy, the central sample (sample 3 of each 5-samples group) was periodically replaced with a certified-material sample.

For ICP-AES measurements, no temporal drift by matrix effects was observed and a single internal-standard method was used (5 mg/L Ge).

\subsubsection{Real-sample methods performances}

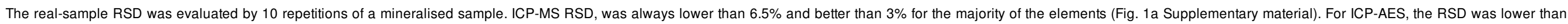
$1.5-\%$ for all the metals (Fig. 1b Supplementary material).

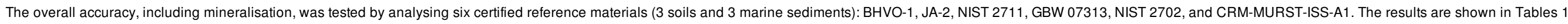

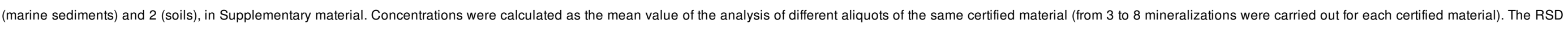
were typically lower than $10 \%$ for ICP-SFMS and lower than $5 \%$ for ICP-AES.

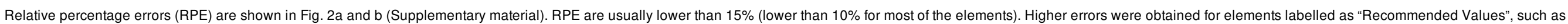

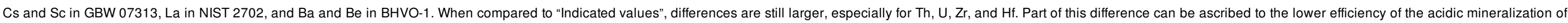

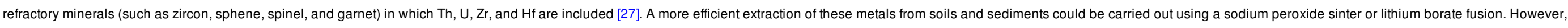
sinter or fusion methods can be affected by contamination from large reagent quantities and possible loss of volatile elements [27].

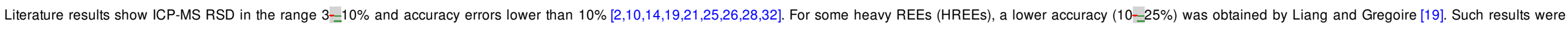

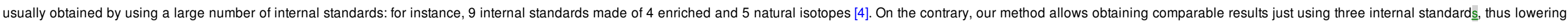
costs (enriched isotopes are expensive) and simplifying the quantification procedure.

\section{Results and discussion}

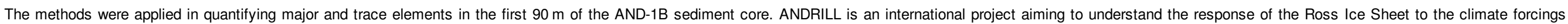

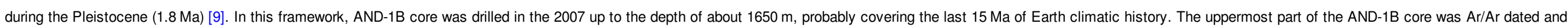
the first $90 \mathrm{~m}$ recorded the sedimentation processes occurred in the last $1.0 \mathrm{Ma}$ [23], a time interval similar to that covered by the EPICA Dome C ice core, drilled in East Antarctica, i.e. about 900 kyr (EPICA [6]).

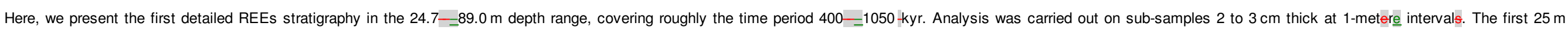

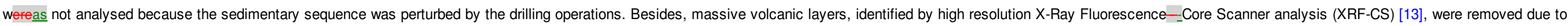
their poor significance in pointing out different patterns in sediment-source contributions from changes in continental glacial fluxes.

Fig. 2 shows the depth profiles of the REEs measured in the sediment samples (La, Ce, Pr, Nd, Sm, Eu, Gd, Tb, Dy, Ho, Er, Tm, Yb, Lu). 


\section{elsevier_MICROC_2131}
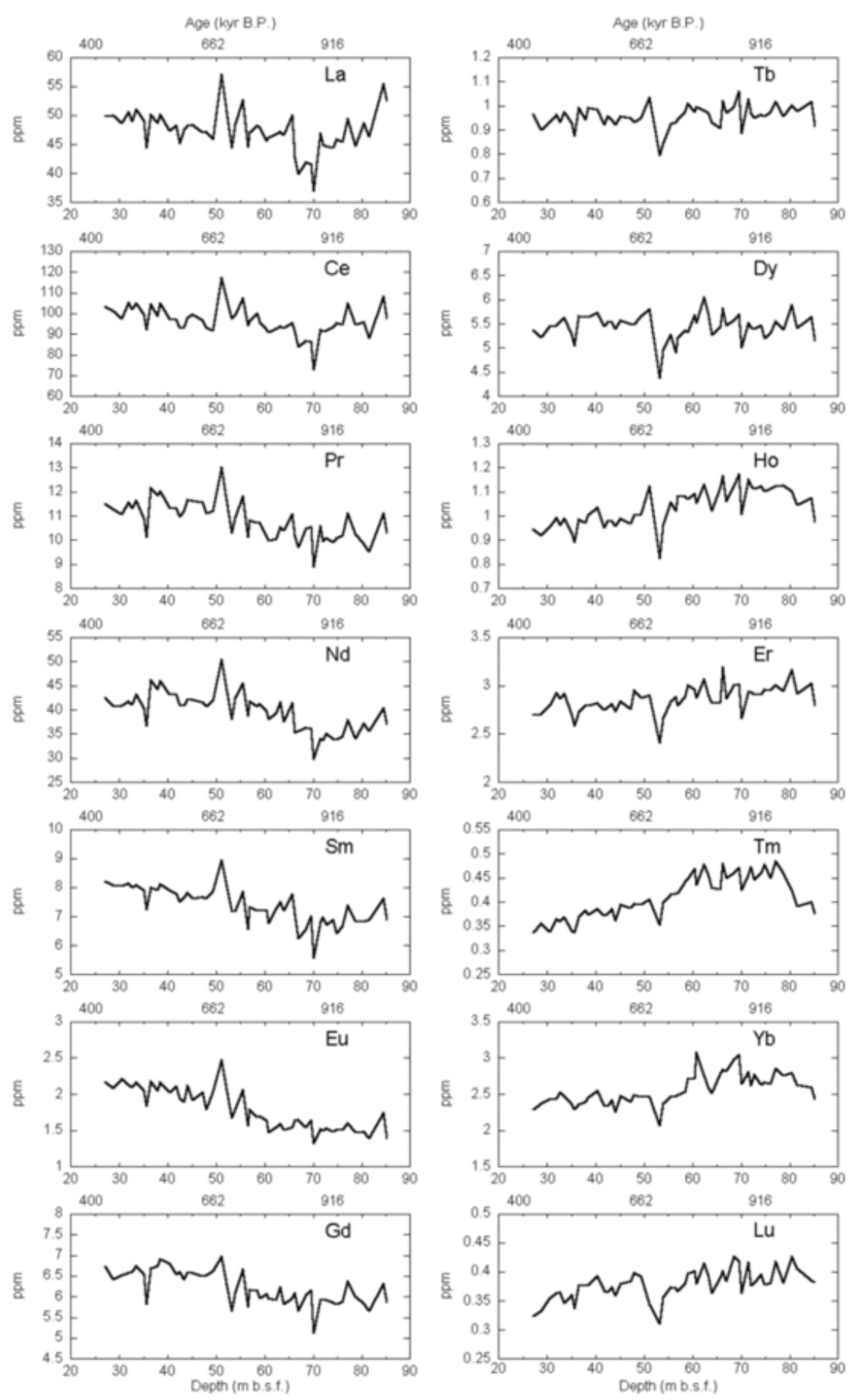

Fig. 2 Stratigraphy of Rare Earth Elements along the analysed core], 
Concentration vs. depth trends of all the REEs determined along the AND-1B core. The bottom $x$-scale represents depth while the up $x$-scale indicates age (as kyr Before Present).

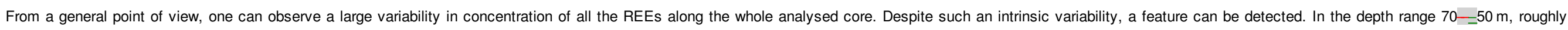

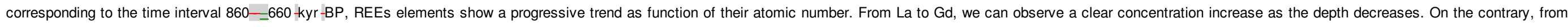

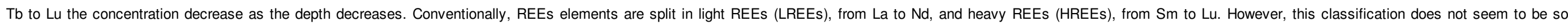

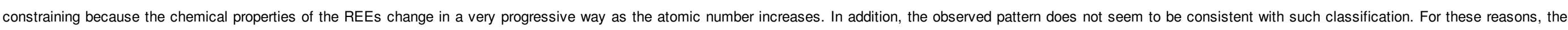

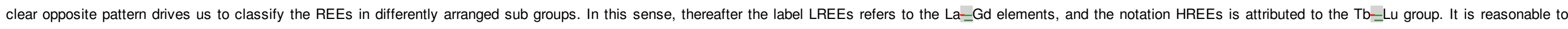

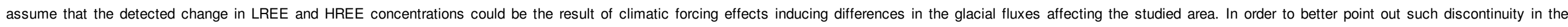

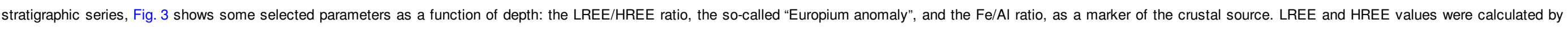

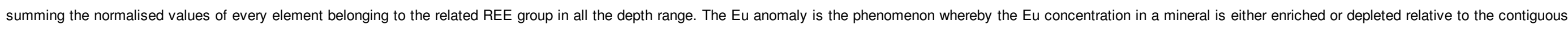

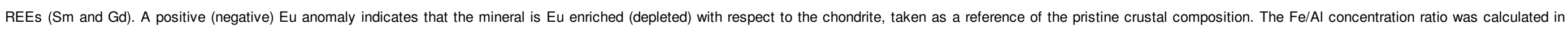
order to: 1. remove the possible effect of differences in elemental concentrations due to the different grain_-size distribution along the core; and 2 . correct for possible dilution effects.
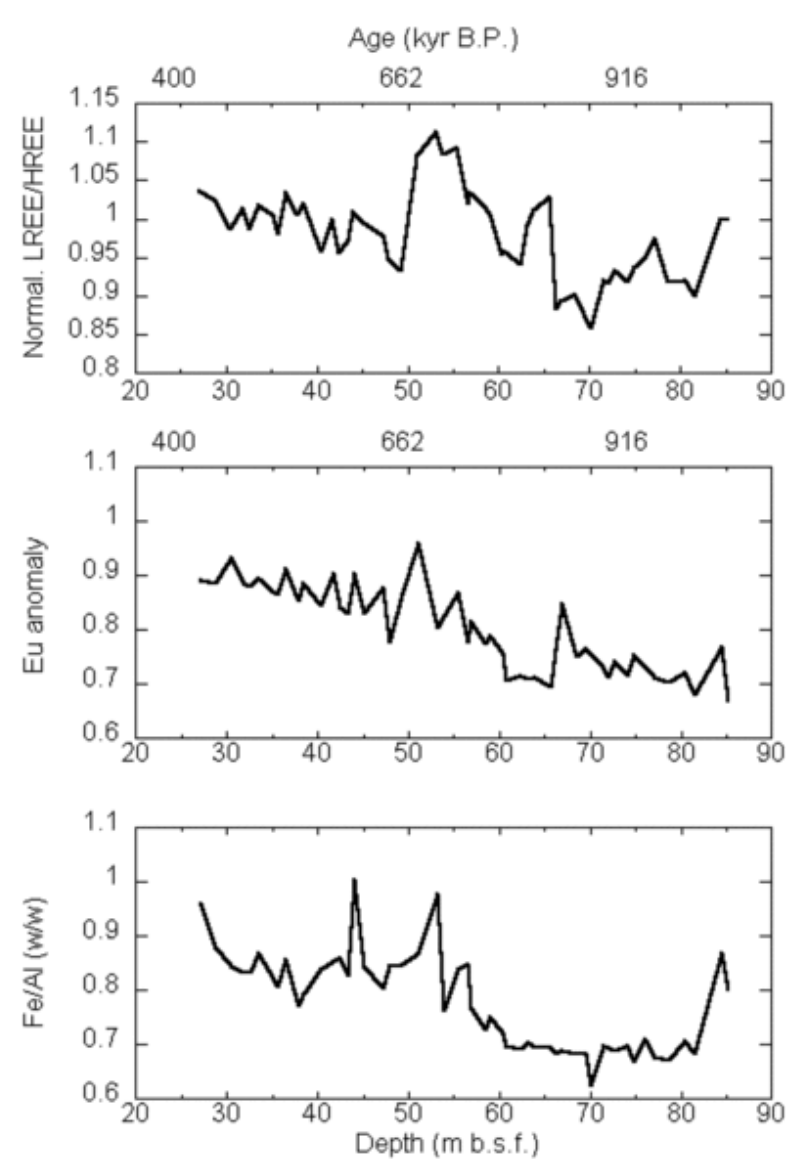

Fig. 3 Stratigraphy of relevant ratios and anomalies along the core.

Trends of Fe/Al, Eu anomaly and normalised LREE/HREE ratio as function of depth along the AND-1B core.

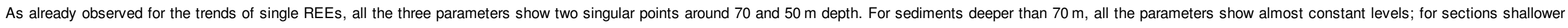




\section{elsevier_MICROC_2131}

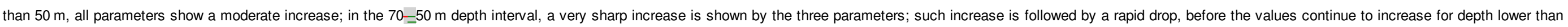

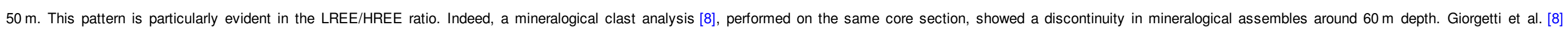

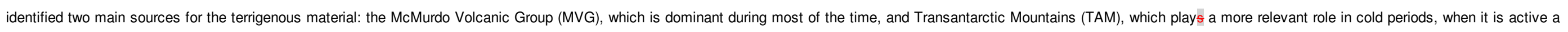
significant glacial flux from such source area to the sediment site. The latter contribution was found to be generally lower along the whole core, but increased up to $50 \%$ in the $50-70 \mathrm{~m}$ depth interval.

\subsection{PMF statistical analysis}

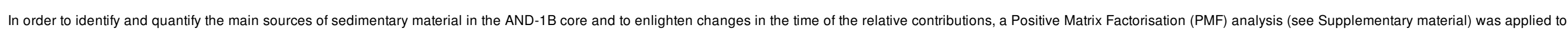

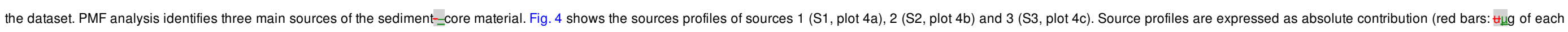

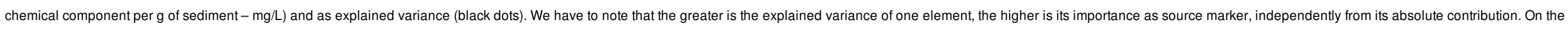

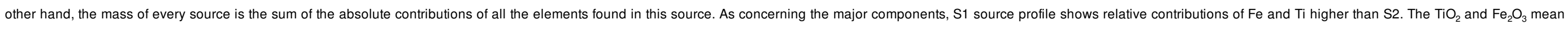

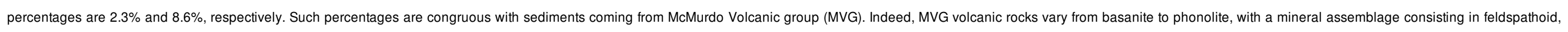

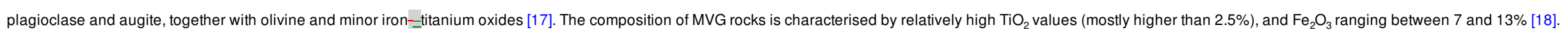



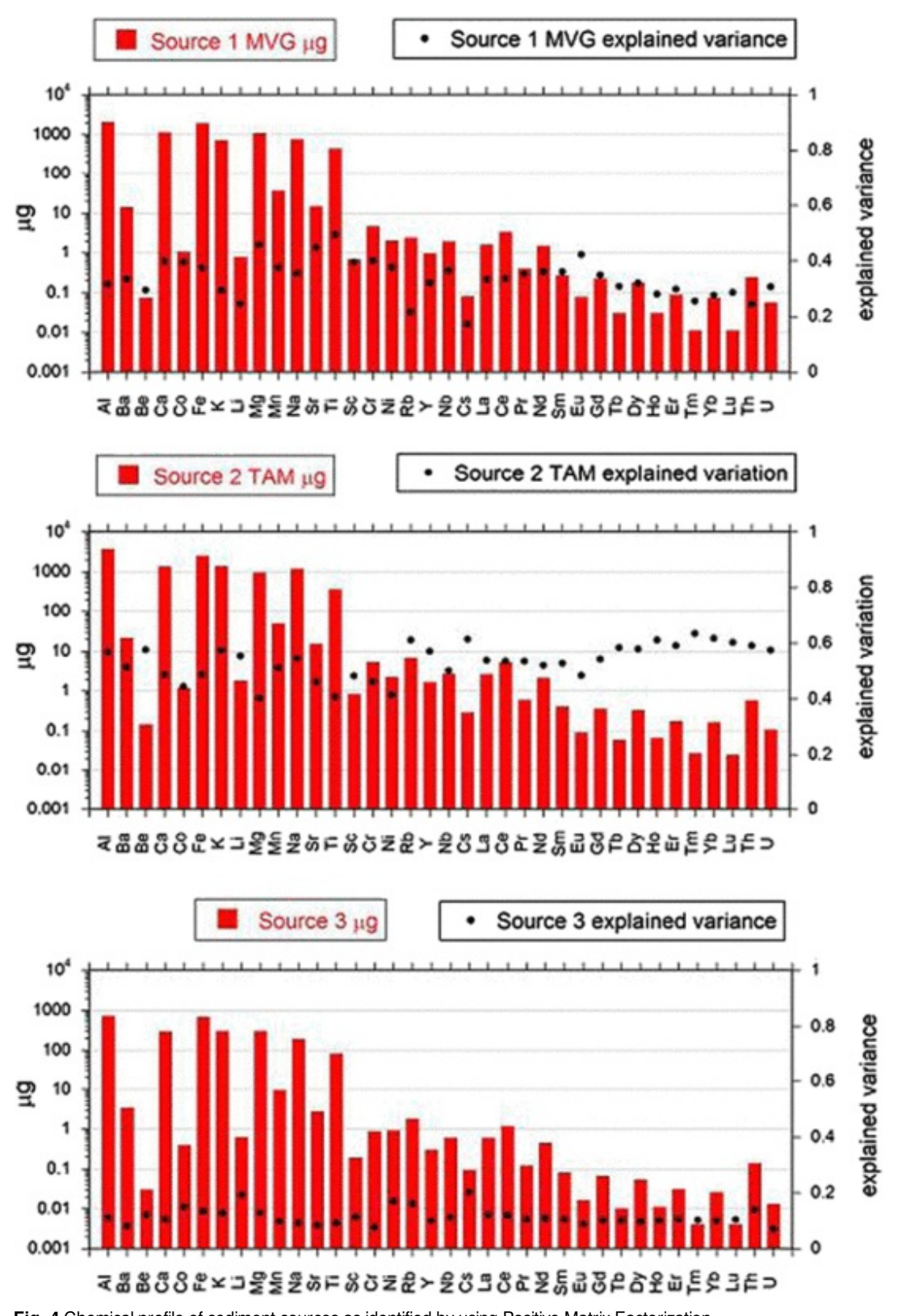

Fig. 4 Chemical profile of sediment sources as identified by using Positive Matrix Factorization.

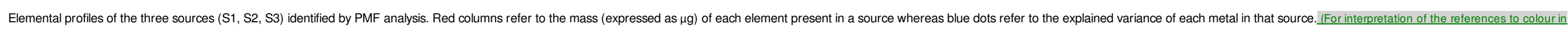
this figure legend, the reader is referred to the web version of this article.)

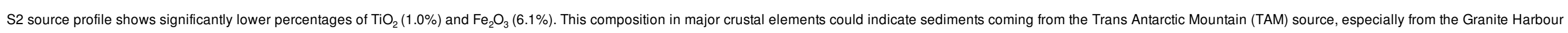

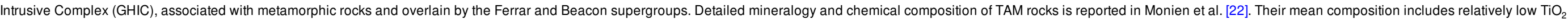




\section{elsevier_MICROC_2131}

and $\mathrm{Fe}_{2} \mathrm{O}_{3}$ percentages $(0.5-1 \%$ and $1-9 \%$, respectively). Such values are consistent with the ones measured in the $\mathrm{S} 2$ source.

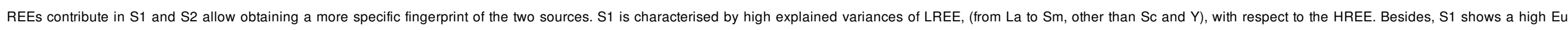
explained variance, which is higher than that of the contiguous REEs, Sm and Gd.

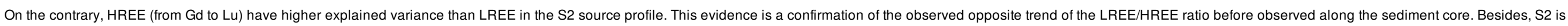
characterizsed by two trace elements: Rb and Cs, that exhibit a higher explained variance with respect to S1. Finally, Eu presents a lower explained variance with respect to the contiguous $\mathrm{Sm}$ and $\mathrm{Gd}$.

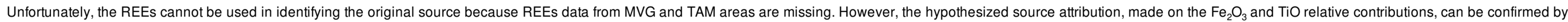
the temporal trend of the $\mathrm{S} 1$ and $\mathrm{S} 2$ sources (see below).

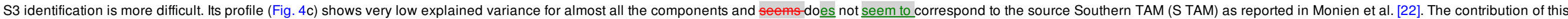

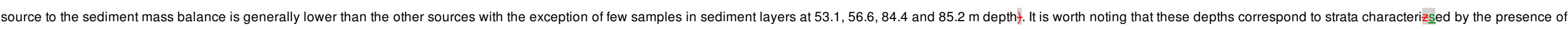

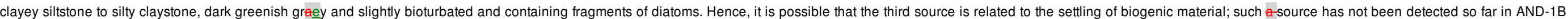
sediment core.

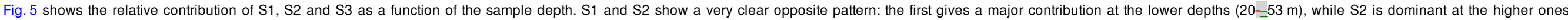

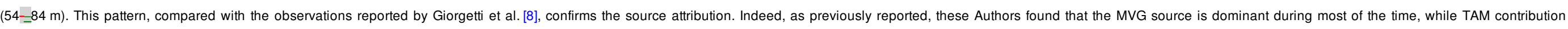
increased up to $50 \%$ in the $50-70 \mathrm{~m}$ depth interval.

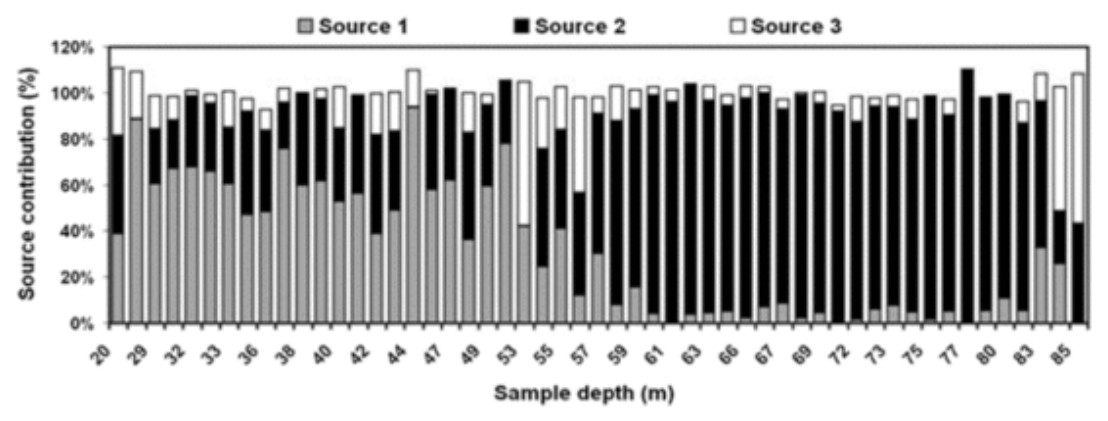

Fig. 5 Source contributions to each sample.

Relative contribution of the three sources identified by PMF analysis ( $\mathrm{S} 1, \mathrm{~S} 2$ and $\mathrm{S} 3$ ) to each sample as a function of the sample depth.

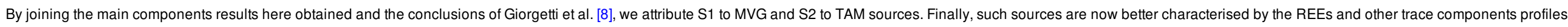

\subsection{Climatic implications}

An in-depth discussion on the climatic implications of the results here obtained is out of the goal of this paper, but some starting points can be here presented.

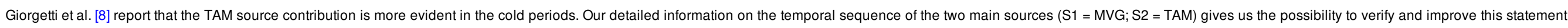
by comparing the sedimentary history of the first $90 \mathrm{~m}$ of the AND-1B core with the EPICA Dome C (EDC) ice core, covering roughly the same temporal interval.

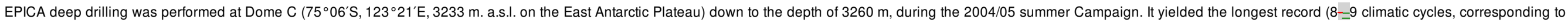

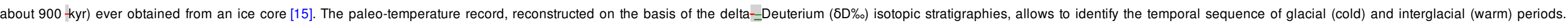

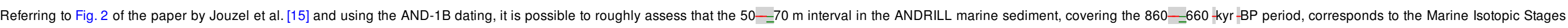

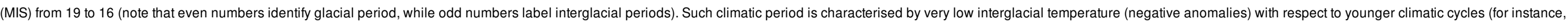

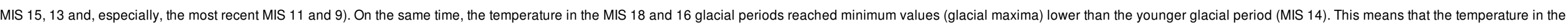




\section{elsevier_MICROC_2131}

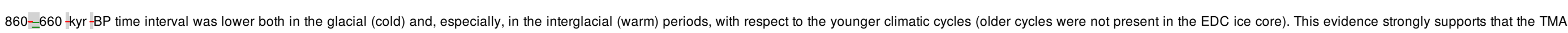

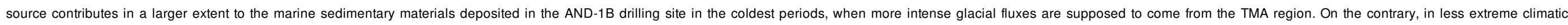
conditions, the MVG source appears to be dominant, due its short distance from the sediment_-core site.

\section{Conclusions}

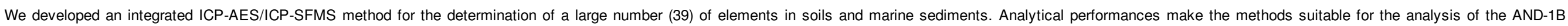
sediment core. Major, trace and REEs elements were measured at $1-\mathrm{m}$ resolution in the $24.7-89.0 \mathrm{~m}$ depth range, covering roughly the time period $400-1050 \mathrm{kyr}$.

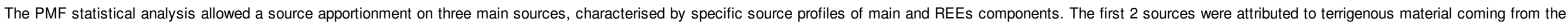

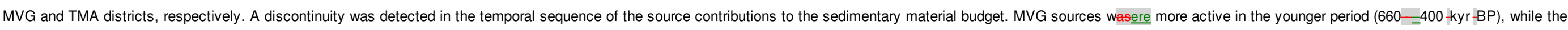

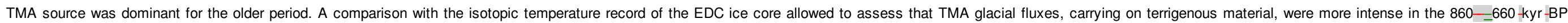

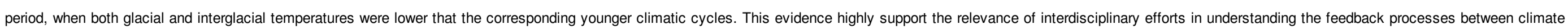
forcing and environmental responses by a compared study of marine and ice cores.

\section{Acknowledgements}

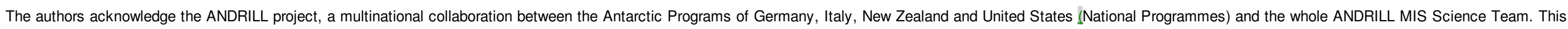
research used samples provided by the Antarctic Marine Geology Research Facility (AMGRF) at Florida State University sponsored by the U.S. National Science Foundation.

This work has been also supported by the RITMARE Flagship Project funded by Italian MInistry of University and Research

\section{Appendix A. Supplementary data}

Supplementary data to this article can be found online at http://dx.doi.org/10.1016/..microc.2015.04.020.

\section{References}

[1]

K.D. Alverson, R.S. Bradley and T.F. Pedersen, Paleoclimate, Global Change and the Future, 2003, Springer Verlag; Berlin Heidelberg, 220.

[2]

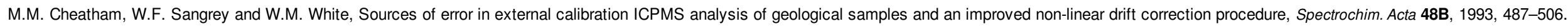

[3]

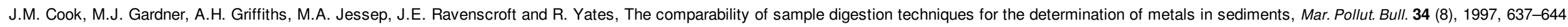

[4]

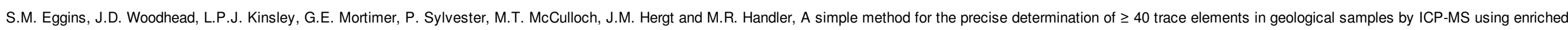
isotope internal standardisation, Chem. Geol. 134, 1997, 311-326.

[5]

E.P.I.C.A. Members, Eight glacial cycles from an Antarctic ice core, Nature 429, 2004, 623-628.

[6]

E.P.I.C.A. Members, One-to-one coupling of glacial climate variability in Greenland and Antarctica, Nature 444, 2006, 195-198.

[7]

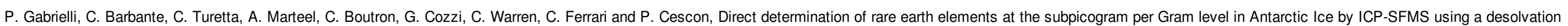




\section{elsevier_MICROC_2131}

system, Anal. Chem. 78, 2006, 1883-1889.

[8]

G. Giorgetti, F. Talarico, S. Sandroni and A. Zeoli, Provenance of Pleistocene sediments in the ANDRILL AND-1B drillcore: clay and heavy mineral data, Glob. Planet. Chang. 69, 2009, 94-102.

[9]

D. Harwood, R. Levy, J. Cowie, F. Florindo, T. Naish, R. Powell and A. Pyne, Deep drilling with the ANDRILL program in Antarctica, Sci. Drill. 3, 2006, 43-45.

[10]

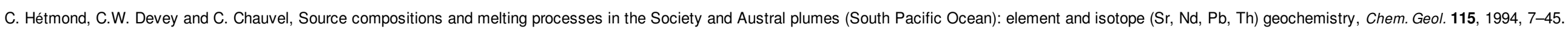

[11]

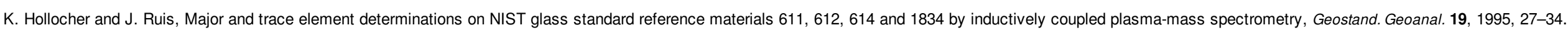

[12]

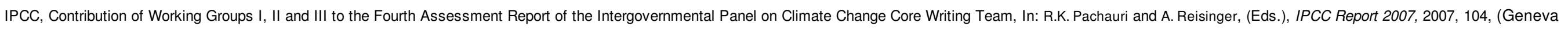
(Switzerland)).

[13]

J.H.F. Jansen, S.J. Van der Gaast, B. Koster and A.J. Vaars, CORTEX, a shipboard XRF-scanner for element analyses in split sediment cores, Mar. Geol. 151, 1998, 143-153.

[14]

G.A. Jenner, H.P. Longerich, B.J. Fryer and S.E. Jackson, Inductively coupled plasma-mass spectrometric analysis of geological samples: a critical evaluation based on case studies, Chem. Geol. 83, 1990, 105-118.

[15]

J. Jouzel, et al., Orbital and millennial Antarctic climate variability over the past 800,000 -years, Science 317, 2007, 793-796.

[16]

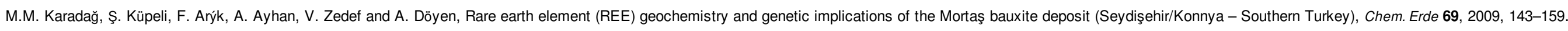

[17]

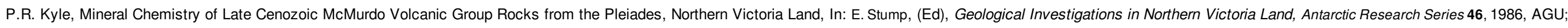
Washington, D.C., 305-333.

[18]

W.E. Le Masurier and J.W. Thomson, (Eds.), Volcanoes of the Antarctic Plate and Southern Oceans, Antarctic Research Series 48, 1990, AGU; Washington, D.C., 97-127.

[19]

Q. Liang and D.C. Gregoire, Determination of trace elements in twenty six Chinese geochemistry reference materials by inductively coupled plasma mass spectrometry, Geostand. Geoanal. 24 (1), 2000, 51-63.

[20]

Q. Liang, H. Jing and D.C. Gregoire, Determination of trace elements in granites by inductively coupled plasma mass spectrometry, Talanta 51, 2000, 507-513.

[21]

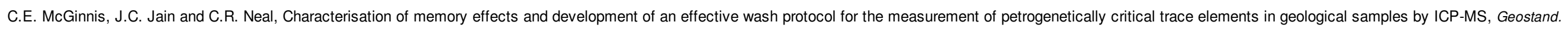

Newslett. 21, 1997, 289-305. 


\section{elsevier_MICROC_2131}

[22]

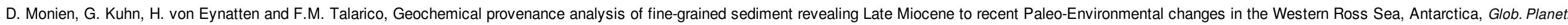
Chang. 96-97, 2012, 41-58.

[23]

T. Naish, et al., Obliquity-paced Pliocene West Antarctic ice sheet oscillations, Nature 458, 2009, 322.

[24]

J.A. Olivares and R.S. Houk, Suppression of analyte signal by various concomitant salts in inductively coupled plasma mass spectrometry, Anal. Chem. 58, 1986, 20-25.

[25]

N.J.G. Pearce, J.A. Westgate, W.T. Perkins and S.J. Preece, The application of ICP-MS methods to tephrochronological problems, Appl. Geochem. 19, $2004,289-322$.

[26]

F. Poitrasson, C. Pin, P. Telouk and J.L. Imbert, Assessment of a simple method for the determination of Nb and Ta at the sub $\mu \mathrm{g} / \mathrm{g}$ level in silicate rocks by ICPMS, Geostand. Newslett. 17, 1993, 209-215.

[27]

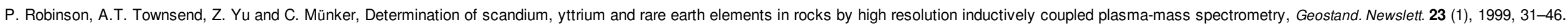

[28]

G. Schönberg, Simultaneous determination of thirthy-seven trace elements in twenty-eight international rock standards by ICP-MS, Geostand. Geoanal. 17, $1993,81-97$.

[29]

A.L. Sharma, O. Alard, S. Elhlou and N.J. Pearson, Evaluation of perchloric versus nitric acid digestion for precise determination of trace and ultra trace elements by ICP-MS, J. Conf. Abstr. Goldschmidt $\mathbf{5}$ (2), $2000,914$.

[30]

S.D. Tanner, D.J. Douglas and J.B. French, Gas and ion dynamics of a three-aperture vacuum interface for inductively coupled plasma-mass spectrometry, Appl. Spectrosc. 48, $1994,1373-1378$.

[31]

S.R. Taylor and S.M. McLennan, The geochemical evolution of the continental crust, Rev. Geophys. 33, 1995, 241-265.

[32]

Q. Xie, J. Jain, M. Sun, R. Kerrich and J. Fan, ICPMS analysis of basalt BIR-1 for trace elements, Geostand. Newslett. 18, 1994, 53-63.

[33]

T. Yokoyama, A. Makishima and E. Nakamura, Evaluation of the coprecipitation of incompatible trace elements with fluoride during silicate rock dissolution by acid digestion, Chem. Geol. 157, 1999, 175-187.

[34]

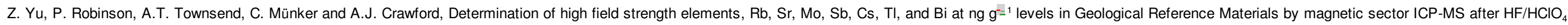

high pressure digestion, Geostand. Geoanal. 24 (1), 2000, 39-50.

\section{Appendix A. Supplementary data}




\section{elsevier_MICROC_2131}

Highlights

- ICP-AES and ICP-SFMS methods optimizsed for geochemical analysis of an Antarctic marine sediment core

- 39 main and trace elements and Rare Earth Elements (REEs) determined on the top $90 \mathrm{~m}$ of ANDRILL core AND-1B (Antarctica)

- PMF (Positive Matrix Factorization) analysis yielded a source apportionment of the main sources in AND-1b marine core . $_{-}$

- Discontinuity in REEs and metal ratios records was highlighted at $660 \mathrm{kyr}-\mathrm{BP}$ and likely due to different source dominance

\section{Queries and Answers}

Query:

Please check the presentation and layout of Table 1 if correct.

Answer: It is correct

Query:

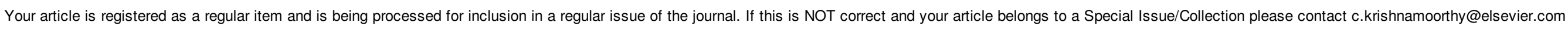
immediately prior to returning your corrections.

Answer: Yes

Query:

Please confirm that given names and surnames have been identified correctly

Answer: Yes

Query:

Please check the presentation of data if correct.

Answer: Correct

Query

The section title "Method setup" is slightly modified fo clarity. Please check.

Answer: Perfectly correct

Query:

Please check the sentence for clarity.

Answer: The sentence sounds as correct to the Authors

Query: 


\section{elsevier_MICROC_2131}

Please check the symbol used here if correct.

\section{Answer: Correct}

Query:

This sentence has been slightly modified for clarity. Please check and confirm if the meaning is still correct.

\section{Answer: Correct}

Query:

One parenthesis has been deleted to balance the delimiters. Please check and confirm if this was done correctly

\section{Answer: I confirm, correct}

Query:

One parenthesis has been added to balance the delimiters. Please check and confirm if this was done correctly.

Answer: Change correct

Query:

Supplementary caption was not provided. Please check the suggested data if appropriate and correct if necessary

Answer: No correction needed 